\title{
Front Matter: Volume 8670
}

, "Front Matter: Volume 8670," Proc. SPIE 8670, Medical Imaging 2013:

Computer-Aided Diagnosis, 867001 (17 April 2013); doi: 10.1117/12.2026548

SPIE Event: SPIE Medical Imaging, 2013, Lake Buena Vista (Orlando Area), Florida, United States 


\title{
PROCEEDINGS OF SPIE
}

\section{Medical Imaging 2013}

\section{Computer-Aided Diagnosis}

\author{
Carol L. Novak \\ Stephen Aylward \\ Editors
}

\section{2-14 February 2013}

Lake Buena Vista, Florida, United States

Sponsored and

SPIE

Cosponsored by

Aeroflex Incorporated $-\mathrm{CREOL}$ - The College Of Optics and Photonics, University of Central Florida (United States) • DQE Instruments, Inc. (Canada) • Medtronic, Inc. • PIXELTEQ,

Multispectral Sensing \& Imaging

Cooperating Organizations

AAPM-American Association of Physicists in Medicine (United States) • APS—American Physiological Society • CARS—Computer Assisted Radiology and Surgery (Germany) Medical Image Perception Society (United States) - Radiological Society of North America (United States) • The DICOM Standards Committee (United States) • Society for Imaging Informatics in Medicine (United States) • Florida Photonics Cluster (United States) World Molecular Imaging Society

Published by

SPIE

Part One of Two Parts

Volume $\mathbf{8 6 7 0}$ 
The papers included in this volume were part of the technical conference cited on the cover and title page. Papers were selected and subject to review by the editors and conference program committee. Some conference presentations may not be available for publication. The papers published in these proceedings reflect the work and thoughts of the authors and are published herein as submitted. The publisher is not responsible for the validity of the information or for any outcomes resulting from reliance thereon.

Please use the following format to cite material from this book:

Author(s), "Title of Paper," in Medical Imaging 2013: Computer-Aided Diagnosis, edited by Carol L. Novak, Stephen Aylward, Proceedings of SPIE Vol. 8670 (SPIE, Bellingham, WA, 2013) Article CID Number.

ISSN: 1605-7422

ISBN: 9780819494443

Published by

SPIE

P.O. Box 10, Bellingham, Washington 98227-0010 USA

Telephone +1 3606763290 (Pacific Time) · Fax +1 3606471445

SPIE.org

Copyright (C) 2013, Society of Photo-Optical Instrumentation Engineers.

Copying of material in this book for internal or personal use, or for the internal or personal use of specific clients, beyond the fair use provisions granted by the U.S. Copyright Law is authorized by SPIE subject to payment of copying fees. The Transactional Reporting Service base fee for this volume is $\$ 18.00$ per article (or portion thereof), which should be paid directly to the Copyright Clearance Center (CCC), 222 Rosewood Drive, Danvers, MA 01923. Payment may also be made electronically through CCC Online at copyright.com. Other copying for republication, resale, advertising or promotion, or any form of systematic or multiple reproduction of any material in this book is prohibited except with permission in writing from the publisher. The CCC fee code is $1605-7422 / 13 / \$ 18.00$.

Printed in the United States of America.

Publication of record for individual papers is online in the SPIE Digital Library.

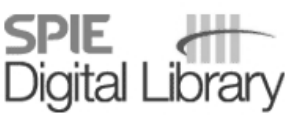

SPIEDigitallibrary.org

Paper Numbering: Proceedings of SPIE follow an e-First publication model, with papers published first online and then in print and on CD-ROM. Papers are published as they are submitted and meet publication criteria. A unique, consistent, permanent citation identifier (CID) number is assigned to each article at the time of the first publication. Utilization of CIDs allows articles to be fully citable as soon as they are published online, and connects the same identifier to all online, print, and electronic versions of the publication. SPIE uses a six-digit CID article numbering system in which:

- The first four digits correspond to the SPIE volume number.

- The last two digits indicate publication order within the volume using a Base 36 numbering

system employing both numerals and letters. These two-number sets start with 00, 01, 02, 03, 04, $05,06,07,08,09,0 \mathrm{~A}, 0 \mathrm{~B} \ldots \mathrm{0Z}$, followed by 10-1Z, 20-2Z, etc.

The CID Number appears on each page of the manuscript. The complete citation is used on the first page, and an abbreviated version on subsequent pages. Numbers in the index correspond to the last two digits of the six-digit CID Number. 


\section{Contents}

\section{Part One}

xix Conference Committee

\section{SESSION 1 NOVEL/OTHER CAD APPLICATIONS}

867002 Hyperspectral signature analysis of skin parameters [8670-1]

S. Vyas, A. Banerjee, Johns Hopkins Univ. (United States); L. Garza, S. Kang, Johns Hopkins Univ. School of Medicine (United States); P. Burlina, Johns Hopkins Univ. (United States)

867003 Down syndrome detection from facial photographs using machine learning techniques [8670-2]

Q. Zhao, Sheikh Zayed Institute for Pediatric Surgical Innovation, Children's National Medical Ctr. (United States); K. Rosenbaum, Children's National Medical Ctr. (United States); R. Sze, Sheikh Zayed Institute for Pediatric Surgical Innovation, Children's National Medical Ctr. (United States); D. Zand, M. Summar, M. G. Linguraru, Children's National Medical Ctr. (United States)

867004 Region detection in medical images using HOG classifiers and a body landmark network [8670-3]

M. Erdt, Fraunhofer IDM@NTU (Germany); O. Knapp, K. Drechsler, S. Wesarg, FraunhoferIGD (Germany)

867005 Automatic segmentation of kidneys from non-contrast CT images using efficient belief propagation [8670-4]

J. Liu, National Institutes of Health Clinical Ctr. (United States); M. G. Linguraru, Sheikh Zayed Institute for Pediatric Surgical Innovation, Children's National Medical Ctr. (United States); S. Wang, R. M. Summers, National Institutes of Health Clinical Ctr. (United States)

867006 Robust detection of renal calculi from non-contract CT images using TV-flow and MSER features [8670-5]

J. Liu, S. Wang, National Institutes of Health Clinical Ctr. (United States); M. G. Linguraru, Sheikh Zayed Institute for Pediatric Surgical Innovation, Children's National Medical Ctr. (United States); R. M. Summers, National Institutes of Health Clinical Ctr. (United States 
867007 Preliminary results of automated removal of degenerative joint disease in bone scan lesion segmentation [8670-6]

G. H. Chu, P. Lo, H. J. Kim, Univ. of California, Los Angeles (United States); M. Auerbach, David Geffen School of Medicine, Univ. of California, Los Angeles (United States); J. Goldin, Univ. of California, Los Angeles (United States) and David Geffen School of Medicine, Univ. of California, Los Angeles (United States); K. Henkel, MedQIA (United States); A. Banola, David Geffen School of Medicine, Univ. of California, Los Angeles (United States); D. Morris, MedQIA (United States); H. Coy, David Geffen School of Medicine, Univ. of California, Los Angeles (United States); M. S. Brown, Univ. of California, Los Angeles (United States) and David Geffen School of Medicine, Univ. of California, Los Angeles (United States)

867008 Segmenting the thoracic, abdominal and pelvic musculature on CT scans combining atlas-based model and active contour model [8670-7]

W. Zhang, J. Liu, J. Yao, R. M. Summers, National Institutes of Health Clinical Ctr. (United States)

867009 Automated measurement of diagnostic angles for hip dysplasia [8670-8] S. de Raedt, I. Mechlenburg, M. Stilling, L. Rømer, K. Søballe, Aarhus Univ. Hospital (Denmark); M. de Bruijne, Erasmus MC (Netherlands) and Univ. of Copenhagen (Denmark)

8670 OA Bone age assessment using support vector regression with smart class mapping [8670-9] D. Haak, J. Yu, H. Simon, RWTH Aachen (Germany); H. Schramm, Fachhochschule Kiel (Germany); T. Seidl, T. M. Deserno, RWTH Aachen (Germany)

8670 OB Cortical thickness estimation of the proximal femur from multi-view dual-energy $X$-ray absorptiometry (DXA) [8670-10]

N. Tsaousis, A. H. Gee, G. M. Treece, K. E. S. Poole, Univ. of Cambridge (United Kingdom)

8670 0C Detection of vertebral degenerative disc disease based on cortical shell unwrapping [8670-11]

H. E. Muñoz, J. Yao, National Institutes of Health Clinical Ctr. (United States); J. E. Burns, Univ. of California, Irvine (United States); R. M. Summers, National Institutes of Health Clinical Ctr. (United States)

\section{SESSION 3 LUNG CAD I}

8670 OD Comparison of demons deformable registration-based methods for texture analysis of serial thoracic CT scans [8670-12]

A. R. Cunliffe, H. A. Al-Hallaq, X. M. Fei, R. E. Tuohy, S. G. Armato III, The Univ. of Chicago Medical Ctr. (United States)

8670 OE Normalization of CT scans reconstructed with different kernels to reduce variability in emphysema measurements [8670-13]

L. Gallardo Estrella, B. van Ginneken, E. M. van Rikxoort, Radboud Univ. Nijmegen Medical Ctr. (Netherlands) 
8670 OF Pulmonary emphysema classification based on an improved texton learning model by sparse representation [8670-14]

M. Zhang, X. Zhou, Gifu Univ. School of Medicine (Japan); S. Goshima, Gifu Univ. Hospital (Japan); H. Chen, C. Muramatsu, T. Hara, Gifu Univ. School of Medicine (Japan); R. Yokoyama, M. Kanematsu, Gifu Univ. Hospital (Japan); H. Fujita, Gifu Univ. School of Medicine (Japan)

8670 OG Normalization of chest radiographs [8670-15]

R. H. H. M. Philipsen, P. Maduskar, L. Hogeweg, B. van Ginneken, Radboud Univ. Nijmegen Medical Ctr. (Netherlands)

$8670 \mathrm{OH}$ Improved texture analysis for automatic detection of tuberculosis (TB) on chest radiographs with bone suppression images [8670-16]

P. Maduskar, L. Hogeweg, R. Philipsen, S. Schalekamp, B. van Ginneken, Radboud Univ. Nijmegen Medical Ctr. (Netherlands)

\section{SESSION 4 LUNG CAD II}

8670 ol A method for automatic matching of multi-timepoint findings for enhanced clinical workflow [8670-17]

L. Raghupathi, M. S. Dinesh, P. R. Devarakota, Siemens Corp., Corporate Technology

(India); G. H. Valadez, M. Wolf, Siemens Healthcare, Inc. (United States)

$8670 \mathrm{0J}$ Tracking time interval changes of pulmonary nodules on follow-up 3D CT images via image-based risk score of lung cancer [8670-18]

Y. Kawata, N. Niki, Univ. of Tokushima (Japan); H. Ohamatsu, National Cancer Ctr. Hospital East (Japan); M. Kusumoto, T. Tsuchida, National Cancer Ctr. (Japan); K. Eguchi, Teikyo Univ. School of Medicine (Japan); M. Kaneko, Tokyo Health Service Association (Japan); N. Moriyama, National Cancer Ctr. for Cancer Prevention and Screening (Japan)

8670 OK Measurement of spiculation index in 3D for solitary pulmonary nodules in volumetric lung CT images [8670-19]

A. K. Dhara, S. Mukhopadhyay, Indian Institute of Technology Kharagpur (India); N. Alam, Bengal Engineering and Science Univ. (India); N. Khandelwal M.D., Postgraduate Institute of Medical Education \& Research (India)

$8670 \mathrm{OL}$ Robust airway extraction based on machine learning and minimum spanning tree [8670-20]

T. Inove, Y. Kitamura, Y. Li, W. Ito, FUJIFILM Corp. (Japan)

\section{SESSION 5 EYE CAD}

$86700 \mathrm{M}$ Automatic age-related macular degeneration detection and staging [8670-21] M. J. J. P. van Grinsven, Y. T. E. Lechanteur, J. P. H. van de Ven, B. van Ginneken, T. Theelen, C. I. Sánchez, Radboud Univ. Nijmegen Medical Ctr. (Netherlands)

$8670 \mathrm{ON}$ Automated detection of microaneurysms using robust blob descriptors [8670-22] K. Adal, S. Ali, D. Sidibé, Univ. de Bourgogne (France); T. Karnowski, Oak Ridge National Lab. (United States); E. Chaum, The Univ. Of Tennessee Health Science Ctr. (United States); F. Mériaudeau, Univ. de Bourgogne (France) 
867000 Changes in quantitative 3D shape features of the optic nerve head associated with age [8670-23]

M. Christopher, L. Tang, J. H. Fingert, T. E. Scheetz, The Univ. of lowa (United States);

M. D. Abramoff, The Univ. of lowa (United States) and U. S. Dept. of Veterans Affairs (United States)

8670 OP Automated retinal vessel type classification in color fundus images [8670-24]

H. YU, S. Barriga, VisionQuest Biomedical, LLC (United States) and Univ. of New Mexico (United States); C. Agurto, S. Nemeth, VisionQuest Biomedical, LLC (United States);

W. Bauman, Retina Institute of South Texas (United States); P. Soliz, VisionQuest Biomedical, LLC (United States)

$86700 Q \quad$ Retrieving clinically relevant diabetic retinopathy images using a multi-class multiple-instance framework [8670-25]

P. S. Chandakkar, R. Venkatesan, B. Li, Arizona State Univ. (United States)

SESSION 6 PANEL DISCUSSION AND HEAD AND NECK I

8670 OR Classification of Alzheimer's disease using regional saliency maps from brain MR volumes [8670-27]

A. Pulido, A. Rueda, E. Romero, Univ. Nacional de Colombia (Colombia)

8670 OS Improved multimodal biomarkers for Alzheimer's disease and mild cognitive impairment diagnosis: data from ADNI [8670-28]

A. Martinez-Torteya, V. Treviño-Alvarado, J. Tamez-Peña, Tecnológico de Monterrey

(Mexico)

\section{SESSION 7 GASTROINTESTINAL AND LIVER CAD}

8670 OU Effect of CADe on radiologists' performance in detection of "difficult" polyps in CT colonography [8670-29]

K. Suzuki, Univ. of Chicago (United States); M. Hori, Osaka Univ. (Japan); G. linuma, National Cancer Ctr. Hospital (Japan); A. H. Dachman, The Univ. of Chicago (United States)

8670 OV Computer-aided detection of early cancer in the esophagus using HD endoscopy images [8670-30]

F. van der Sommen, S. Zinger, Technische Univ. Eindhoven (Netherlands); E. J. Schoon, Catharina-ziekenhuis (Netherlands); P. H. N. de With, Technische Univ. Eindhoven (Netherlands)

8670 OW Low-dose dual-energy electronic cleansing for fecal-tagging CT colonography [8670-31] W. Cai, D. Zhang, Massachusetts General Hospital (United States) and Harvard Medical School (United States); J.-G. Lee, Univ. of Pittsburgh (United States); H. Yoshida, Massachusetts General Hospital (United States) and Harvard Medical School (United States) 
8670 0X Blood vessel-based liver segmentation through the portal phase of a CT dataset [8670-32] A. S. Maklad, M. Matsuhiro, H. Suzuki, Y. Kawata, N. Niki, Univ. of Tokushima (Japan); N. Moriyama, National Cancer Ctr. (Japan); T. Utsunomiya, M. Shimada, Univ. Of Tokushima (Japan)

8670 OY Image patch-based method for automated classification and detection of focal liver lesions on CT [8670-33]

M. Safdari, R. Pasari, D. Rubin, Stanford Univ. (United States); H. Greenspan, Tel-Aviv Univ. (Israel)

\section{SESSION 8 HEAD AND NECK CAD II}

$86700 Z$ Visual analysis of longitudinal brain tumor perfusion [8670-34]

S. Glaßer, S. Oeltze, Otto-von-Guericke Univ. of Magdeburg (Germany); U. Preim, Univ. Hospital Magdeburg (Germany); A. Bjørnerud, Rikshospitalet-Radiumhospitalet Medical Ctr., Univ. of Oslo (Norway); H. Hauser, Univ. of Bergen (Norway); B. Preim, Otto-vonGuericke Univ. of Magdeburg (Germany)

867010 Differentiating cerebral lymphomas and GBMs featuring luminance distribution analysis [8670-35]

T. Yamasaki, Cornell Univ. (United States), The Univ. of Tokyo (Japan) and Japan Society for Promotion of Science (Japan); T. Chen, Cornell Univ. (United States); T. Hirai,

R. Murakami, Kumamoto Univ. (Japan)

867011 Assessment of quantitative cortical biomarkers in the developing brain of preterm infants [8670-36]

P. Moeskops, M. J. N. L. Benders P. C. Pearlman, K. J. Kersbergen, A. Leemans, M. A. Viergever, I. Išgum, Univ. Medical Ctr. Utrecht (Netherlands)

867012 Computer-aided diagnosis of acute ischemic stroke based on cerebral hypoperfusion using 4D CT angiography [8670-37]

J. P. Charbonnier, E. J. Smit, M. A. Viergever, B. K. Velthuis, P. C. Vos, Univ. Medical Ctr. Utrecht (Netherlands)

867013 Automatic detection and segmentation of ischemic lesions in computed tomography images of stroke patients [8670-38]

P. C. Vos, J. M. Biesbroek, N. A. Weaver, B. K. Velthuis, M. A. Viergever, Univ. Medical Ctr. Utrecht (Netherlands)

867014 Detection of white matter lesions in cerebral small vessel disease [8670-39]

M. M. Riad, Radboud Univ. Nijmegen Medical Ctr. (Netherlands); B. Platel, Fraunhofer MEVIS (Germany); F.-E. de Leeuw, N. Karssemeijer, Radboud Univ. Nijmegen Medical Ctr. (Netherlands) 
867015 Automatic stent strut detection in intravascular OCT images using image processing and classification technique [8670-40]

H. Lu, M. Gargesha, Z. Wang, Case Western Reserve Univ. (United States); D. Chamie, G. F. Attizani, T. Kanaya, Harrington Heart \& Vascular Institute, Univ. Hospitals Case Medical Ctr. (United States); S. Ray, Case Western Reserve Univ. (United States); M. A. Costa, Harrington Heart \& Vascular Institute, Univ. Hospitals Case Medical Ctr. (United States); A. M. Rollins, Case Western Reserve Univ. (United States); H. G. Bezerra, Harrington Heart \& Vascular Institute, Univ. Hospitals Case Medical Ctr. (United States); D. L. Wilson, Case Western Reserve Univ. (United States)

867016 Computerized detection of non-calcified plaques in coronary CT angiography: topological soft-gradient detection method for plaque prescreening [8670-41]

J. Wei, C. Zhou, H.-P. Chan, A. Chughtai, S. Patel, P. Agarwal, J. Kuriakose, L. Hadjiiski,

E. Kazerooni, Univ. of Michigan (United States)

867017 Computer-aided scheme for functional index computation of left ventricle in cardiac CTA: segmentation and partitioning of left ventricle [8670-42] H. Huang, X. Zhuang, Y. Shao, T. Lan, L. Liu, Q. Li, Shanghai Advanced Research Institute (China)

867018 Computer-based assessment of left ventricular wall stiffness in patients with ischemic dilated cardiomyopathy [8670-43]

Y. SU, S. K. Teo, A*STAR Institute of High Performance Computing (Singapore); R. S. Tan, National Heart Ctr. (Singapore) and Duke-NUS Graduate Medical School (Singapore); C. W. Lim, A*STAR Institute of High Performance Computing (Singapore); L. Zhong, National Heart Ctr. (Singapore)

867019 Patient-specific coronary artery blood flow simulation using myocardial volume partitioning [8670-44]

K. H. Kim, Samsung Advanced Institute of Technology (Korea, Republic of); D. Kang, The Univ. of Southern California (United States); N. Kang, J.-Y. Kim, H.-E. Lee, J. D. K. Kim, Samsung Advanced Institute of Technology (Korea, Republic of)

\section{SESSION 10 BREAST CAD I}

$86701 \mathrm{~A}$ Automated assessment of bilateral breast volume asymmetry as a breast cancer biomarker during mammographic screening [8670-45]

A. C. Williams, A. Hitt, Middle Tennessee State Univ. (United States); S. Voisin, G. Tourassi, Oak Ridge National Lab. (United States)

8670 1B A fully-automated software pipeline for integrating breast density and parenchymal texture analysis for digital mammograms: parameter optimization in a case-control breast cancer risk assessment study [8670-46]

Y. Zheng, Y. Wang, B. M. Keller, E. Conant, J. C. Gee, D. Kontos, Perelman School of Medicine at the Univ. of Pennsylvania (United States) 
8670 1C Fully-automated fibroglandular tissue segmentation and volumetric density estimation in breast MRI by integrating a continuous max-flow model and a likelihood atlas [8670-47] S. Wu, Computational Breast Imaging Group, Univ. of Pennsylvania (United States); S. P. Weinstein, E. F. Conant, Hospital of the Univ. of Pennsylvania (United States); D. Kontos, Computational Breast Imaging Group, Univ. of Pennsylvania (United States)

8670 ID Breast segmentation in MR images using three-dimensional spiral scanning and dynamic programming [8670-48] L. Jiang, Y. Lian, Shanghai Advanced Research Institute (China); Y. Gu, Fudan Univ. Cancer Hospital (China); Q. Li, Shanghai Advanced Research Institute (China)

8670 IE Symmetry-based detection and diagnosis of DCIS in breast MRI [8670-49]

A. Srikantha, Fraunhofer MEVIS (Germany) and Le2i, CNRS, Univ. de Bourgone (France); M. T. Harz, Fraunhofer MEVIS (Germany); G. Newstead, The Univ. of Chicago (United States); L. Wang, Fraunhofer MEVIS (Germany); B. Platel, Fraunhofer MEVIS (Netherlands) and Radboud Univ. Nijmegen Medical Ctr. (Netherlands); R. M. Mann, Radboud Univ. Nijmegen Medical Ctr. (Netherlands); H. K. Hahn, H. O. Peitgen, Fraunhofer MEVIS (Germany)

$8670 \mathrm{IF}$ Association between bilateral asymmetry of kinetic features computed from the DCE-MRI images and breast cancer [8670-50]

Q. Yang, L. Li, Hangzhou Dianzi Univ. (China); J. Zhang, Zhejiang Cancer Hospital (China); C. Zhang, Hangzhou Dianzi Univ. (China); B. Zheng, Hangzhou Dianzi Univ. (China) and Univ. of Pittsburgh (United States)

\section{SESSION 11 PROSTATE AND ONCOLOGY}

$86701 G$ A prostate cancer computer-aided diagnosis system using multimodal magnetic resonance imaging and targeted biopsy labels [8670-51]

P. Liu, S. Wang, National Institutes of Health Clinical Ctr. (United States); B. Turkbey, K. Grant, P. Pinto, P. Choyke, National Cancer Ctr., National Institutes of Health (United States);

B. J. Wood, R. M. Summers, National Institutes of Health Clinical Ctr. (United States)

$86701 \mathrm{H} \quad$ A study of $\mathrm{T}_{2}$-weighted MR image texture features and diffusion-weighted MR image features for computer-aided diagnosis of prostate cancer [8670-52]

Y. Peng, Y. Jiang, T. Antic, M. L. Giger, S. Eggener, A. Oto, The Univ. of Chicago (United States)

$867011 \quad$ Ultrasound RF time series for tissue typing: first in vivo clinical results [8670-53] M. Moradi, S. S. Mahdavi, G. Nir, E. C. Jones, S. L. Goldenberg, S. E. Salcudean, The Univ. of British Columbia (Canada)

$86701 \mathrm{~J}$ Iterative multiple reference tissue method for estimating pharmacokinetic parameters on prostate DCE MRI [8670-54]

S. B. Ginsburg, Case Western Reserve Univ. (United States); B. N. Bloch, Boston Univ. School of Medicine (United States); N. M. Rofsky, The Univ. of Texas Southwestern Medical Ctr. (United States); E. M. Genega, Beth Israel Deaconess Medical Ctr. (United States); R. E. Lenkinski, The Univ. of Texas Southwestern Medical Ctr. (United States); A. Madabhushi, Case Western Reserve Univ. (United States) 
$86701 \mathrm{~K}$ Automatic abdominal lymph node detection method based on local intensity structure analysis from 3D x-ray CT images [8670-55]

Y. Nakamura, Y. Nimura, Nagoya Univ. (Japan); T. Kitasaka, S. Mizuno, Aichi Institute of Technology (Japan); K. Furukawa, H. Goto, M. Fujiwara, Nagoya Univ. School of Medicine (Japan); K. Misawa, Aichi Cancer Ctr. Hospital (Japan); M. Ito, National Cancer Ctr. Hospital East (Japan); S. Nawano, International Univ. of Health and Welfare Mita Hospital (Japan); K. Mori, Nagoya Univ. (Japan)

\section{Part Two}

\section{SESSION 12 BREAST CAD II}

$86701 \mathrm{~L}$ Detection of microcalcifications in breast tomosynthesis reconstructed with multiscale bilateral filtering regularization [8670-56]

R. K. Samala, H. P. Chan, Y. LU, L. Hadjiyski, J. Wei, Univ. of Michigan, Ann Arbor (United States); B. Sahiner, U.S. Food and Drug Administration (United States); M. Helvie, Univ. of Michigan, Ann Arbor (United States)

$86701 \mathrm{M}$ Neural network training by maximization of the area under the ROC curve: application to characterization of masses on breast ultrasound as malignant or benign [8670-58]

B. Sahiner, X. He, W. Chen, U.S. Food and Drug Administration (United States); H. P. Chan, L. Hadjiiski, Univ. of Michigan (United States); N. Petrick, U.S. Food and Drug Administration (United States)

$86701 \mathrm{~N}$ Finding lesion correspondences in different views of automated 3D breast ultrasound [8670-59]

T. Tan, Radboud Univ. Nijmegen Medical Ctr. (Netherlands); B. Platel, Fraunhofer MEVIS (Germany); M. Hicks, R. M. Mann, N. Karssemeijer, Radboud Univ. Nijmegen Medical Ctr. (Netherlands)

867010 Computer-aided lesion diagnosis in B-mode ultrasound by border irregularity and multiple sonographic features [8670-60]

J.-H. Lee, Keimyung Univ. (Korea, Republic of); Y. K. Seong, C.-H. Chang, Samsung Advanced Institute of Technology (Korea, Republic of); E. Y. Ko, SAMSUNG Medical Ctr. (Korea, Republic of); B. H. Cho, Samsung Advanced Institute of Technology (Korea, Republic of); J. Ku, Keimyung Univ. (Korea, Republic of); K.-G. Woo, Samsung Advanced Institute of Technology (Korea, Republic of)

8670 IP A robust region-based active contour model with point classification for ultrasound breast lesion segmentation [8670-61]

Z. Liu, L. Zhang, H. Ren, J.-Y. Kim, Samsung Advanced Institute of Technology (China)

$86701 Q$ Fast microcalcification detection in ultrasound images using image enhancement and threshold adjacency statistics [8670-65]

B. H. Cho, C. Chang, Samsung Advanced Institute of Technology (Korea, Republic of); J.-H. Lee, Keimyung Univ. School of Medicine (Korea, Republic of); E. Y. Ko, SAMSUNG Medical Ctr. (Korea, Republic of); Y. K. Seong, K.-G. Woo, Samsung Advanced Institute of Technology (Korea, Republic of) 
8670 IR Psychophysical similarity measure based on multi-dimensional scaling for retrieval of similar images of breast masses on mammograms [8670-62]

K. Nishimura, C. Muramatsu, Gifu Univ. School of Medicine (Japan); M. Oiwa, M. Shiraiwa, T. Endo, National Hospital Organization, Nagoya Medical Ctr. (Japan); K. Doi, Gunma Prefectural Collage of Health Sciences (Japan) and The Univ. of Chicago (United States); H. Fujita, Gifu Univ. School of Medicine (Japan)

8670 is Automatic localization of the nipple in mammograms using Gabor filters and the Radon transform [8670-63]

J. Chakraborty, S. Mukhopadhyay, Indian Institute of Technology Kharaguur (India);

R. M. Rangayyan, Schulich School of Engineering, Univ. of Calgary (Canada) and Univ. of Calgary (Canada); A. Sadhu, Medical College and Hospital Kolkata (India);

P. M. Azevedo-Marques, School of Medicine of Ribeirão Preto, Univ. of São Paulo (Brazil)

$86701 \mathrm{~T}$ Preliminary investigation on CAD system update: effect of selection of new cases on classifier performance [8670-64]

C. Muramatsu, K. Nishimura, T. Hara, H. Fujita, Gifu Univ. School of Medicine (Japan)

$86701 \mathrm{U}$ Model-based position correlation between breast images [8670-66]

J. Georgii, F. Zöhrer, H. K. Hahn, Fraunhofer MEVIS (Germany)

$86701 \mathrm{~V}$ Boosting framework for mammographic mass classification with combination of CC and MLO view information [8670-67]

D. H. Kim, J. Y. Choi, Y. M. Ro, KAIST (Korea, Republic of)

$86701 \mathrm{X}$ Neural networks combined with region growing techniques for tumor detection in $\left[{ }^{18} \mathrm{~F}\right]-$ fluorothymidine dynamic positron emission tomography breast cancer studies [8670-69]

Z. Cseh, Hammersmith Hospital, Imperial College London (United Kingdom) and Univ. of Kaposvar (Hungary); L. Kenny, J. Swingland, S. Bose, Hammersmith Hospital, Imperial College London (United Kingdom); F. E. Turheimer, Hammersmith Hospital, Imperial College London (United Kingdom) and King's College London (United Kingdom)

$86701 Y$ Improving positive predictive value in computer-aided diagnosis using mammographic mass and microcalcification confidence score fusion based on co-location information [8670-70]

S. H. Lee, D. H. Kim, J. Y. Choi, Y. M. Ro, KAIST (Korea, Republic of)

867012 Automated detection scheme of architectural distortion in mammograms using adaptive Gabor filter [8670-71]

R. Yoshikawa, A. Teramoto, Fujita Health Univ. (Japan); T. Matsubara, Nagoya Bunri Univ. (Japan); H. Fujita, Gifu Univ. School of Medicine (Japan)

867020 A pairwise image analysis with sparse decomposition [8670-72]

A. Boucher, F. Cloppet, N. Vincent, Univ. Paris Descartes (France)

$867021 \quad$ Visual words based approach for tissue classification in mammograms [8670-73]

I. Diamant, Tel-Aviv Univ. (Israel); J. Goldberger, Bar-llan Univ. (Israel); H. Greenspan, Tel-

Aviv Univ. (Israel) 
867022 Improving breast cancer classification with mammography, supported on an appropriate variable selection analysis [8670-74]

N. Pérez, M. A. Guevara, Univ. do Porto (Portugal); A. Silva, Univ. de Aveiro (Portugal)

867023 Predictive features of breast cancer on Mexican screening mammography patients [8670-75]

J. Rodriguez-Rojas, Tecnologico de Monterrey (Mexico); M. Garza-Montemayor, Hospital San Jose Tec de Monterrey (Mexico); V. Trevino-Alvarado, J. Tamez-Pena, Tecnologico de Monterrey (Mexico)

867024 Automatic assessment of the quality of patient positioning in mammography [8670-76] T. Bülow, K. Meetz, D. Kutra, T. Netsch, R. Wiemker, M. Bergtholdt, J. Sabczynski, Philips Research (Germany); N. Wieberneit, M. Freund, I. Schulze-Wenck, Philips Medical Systems (Germany)

867025 Automatic 3D lesion segmentation on breast ultrasound images [8670-77] H.-C. Kuo, Univ. of Illinois at Chicago (United States) and The Univ. of Chicago (United States); M. L. Giger, I. Reiser, K. Drukker, A. Edwards, C. A. Sennett, The Univ. of Chicago (United States)

867026 Texture feature standardization in digital mammography for improving generalizability across devices [8670-79]

Y. Wang, B. M. Keller, Y. Zheng, R. J. Acciavatti, J. C. Gee, A. D. A. Maidment, D. Kontos, Perelman School of Medicine at the Univ. of Pennsylvania (United States)

867027 Quantitative evaluation of automatic methods for lesions detection in breast ultrasound images [8670-78]

K. D. Marcomini, H. Schiabel, A. A. O. Carneiro, Univ. de São Paulo (Brazil)

\section{POSTER SESSION: GASTROINTESTINAL AND LIVER}

867028 A clinically viable capsule endoscopy video analysis platform for automatic bleeding detection [8670-80]

S. Yi, H. Jiao, J. Xie, M. Peter, Xyken, LLC (United States); J. A. Leighton, S. Pasha, L. Rentz, Mayo Clinic (United States); M. Abedi, Gastroenterology Associates of Northern Virginia (United States)

$867029 \quad$ A method for quickly and exactly extracting hepatic vein [8670-81]

Q. Xiong, R. Yuan, L. Wang, Huazhong Univ. of Science and Technology (China) and Wuhan National Lab. for Optoelectronics (China); Y. Wang, Z. Li, D. Hu, Tongji Medical College, Huazhong Univ. of Science and Technology (China); Q. Xie, Huazhong Univ. of Science and Technology (China) and Wuhan National Lab. for Optoelectronics (China)

8670 2A A dimension reduction strategy for improving the efficiency of computer-aided detection for CT colonography [8670-82]

B. Song, Stony Brook Univ., SUNY (United States); G. Zhang, Fourth Military Medical Univ. (China); H. Wang, W. Zhu, Z. Liang, Stony Brook Univ., SUNY (United States) 
$86702 \mathrm{~B}$ Supine and prone registration of the colon for CT colonography based on dynamic programming technique [8670-83]

M. Oda, E. Fukano, Nagoya Univ. (Japan); T. Kitasaka, Aichi Institute of Technology (Japan); T. Takayama, Univ. of Tokushima (Japan); H. Takabatake, Sapporo-Minami Sanjyo Hospital (Japan); M. Mori, Sapporo Kosei General Hospital (Japan); H. Natori, Keiwakai Nishioka Hospital (Japan); S. Nawano, International Univ. of Health and Welfare Mita Hospital (Japan); K. Mori, Nagoya Univ. (Japan)

$86702 \mathrm{C}$ Comparison of texture models for efficient ultrasound image retrieval [8670-84] M. Bansal, V. Sharma, S. Singh, Panjab Univ. (India)

$86702 \mathrm{E}$ Volumetric detection of flat lesions for minimal-preparation dual-energy CT colonography [8670-86]

J. J. Näppi, Massachusetts General Hospital (United States) and Harvard Medical School (United States); S. H. Kim, Seoul National Univ. Hospital (Korea, Republic of); H. Yoshida, Massachusetts General Hospital (United States) and Harvard Medical School (United States)

86702 F A shape constrained MAP-EM algorithm for colorectal segmentation [8670-87] H. Wang, Stony Brook Univ., SUNY (United States) and Beihang Univ. (China); L. Li, College of Staten Island, SUNY (United States); B. Song, F. Han, Z. Liang, Stony Brook Univ., SUNY (United States)

\section{POSTER SESSION: EYE}

$86702 \mathrm{G}$ Optic disk localization by a robust fusion method [8670-88] J. Zhang, Nanyang Technological Univ. (Singapore); F. Yin, D. W. K. Wong, J. Liu, A*STAR Institute for Infocomm Research (Singapore); M. Baskaran, C.-Y. Cheng, T. Y. Wong, Singapore Eye Research Institute (Singapore)

$86702 \mathrm{H} \quad$ Region-based multi-step optic disk and cup segmentation from color fundus image [8670-89]

D. Xiao, Australian e-Health Research Ctr., CSIRO (Australia); J. Lock, Australian e-Health Research Ctr., CSIRO (Australia) and Royal Perth Hospital (Australia); J. M. Manresa, Clinica Cadarso (Spain); J. Vignarajan, Australian e-Health Research Ctr., CSIRO (Australia); M.-L. Tay-Kearney, Royal Perth Hospital (Australia); Y. Kanagasingam, Australian e-Health Research Ctr., CSIRO (Australia)

867021 Computerized detection of retina blood vessel using a piecewise line fitting approach [8670-90]

S. Gu, Univ. of Pittsburgh (United States); Y. Zhen, N. Wang, Beijing Tongren Hospital, Capital Medical Univ. (China); J. Pu, Univ. of Pittsburgh (United States)

$86702 \mathrm{~J}$ Automatic conjunctival provocation test combining Hough circle transform and selfcalibrated color measurements [8670-91]

S. R. Bista, RWTH Aachen Univ. (Germany) and Univ. de Bourgogne (France); I. Sárándi, RWTH Aachen Univ. (Germany); S. Dogan, A. Astvatsatourov, R. Mösges, Univ. of Cologne (Germany); T. M. Deserno, RWTH Aachen Univ. (Germany) 
$86702 \mathrm{~K}$ Training set optimization and classifier performance in a top-down diabetic retinopathy screening system [8670-92]

J. Wigdahl, C. Agurto, VisionQuest Biomedical, LLC (United States) and Univ. of New Mexico (United States); V. Murray, S. Barriga, P. Soliz, VisionQuest Biomedical, LLC (United States)

POSTER SESSION: HEAD AND NECK

$86702 \mathrm{~L} \quad$ White matter injury detection in neonatal MRI [8670-93]

I. Cheng, N. Hazari, A. Firouzmanesh, R. Shen, Univ. of Alberta (Canada); S. Miller, SickKids Hosptial (Canada); K. Poskitt, BC Children's Hospital (Canada); A. Basu, Univ. of Alberta (Canada)

$86702 \mathrm{M}$ Risk assessment of sleeping disorder breathing based on upper airway centerline evaluation [8670-94]

N. Alsufyani, R. Shen, I. Cheng, P. Major, Univ. of Alberta (Canada)

$86702 \mathrm{~N}$ Statistical shape modeling of human cochlea: alignment and principal component analysis [8670-96]

A. A. Poznyakovskiy, T. Zahnert, Universitätsklinikum Carl Gustav Carus Dresden (Germany); B. Fischer, Fraunhofer-Institut für Zerstörungsfreie Prüfverfahren (Germany); N. Lasurashvili, Universitätsklinikum Carl Gustav Carus Dresden (Germany); Y. Kalaidzidis, Max-PlanckInstitut für molekulare Zellbiologie und Genetik (Germany) and Belozersky Institute PhysicoChemical Biology, Moscow State Univ. (Russian Federation); D. Mürbe, Saxonian CochleaImplant-Ctr., Universitätsklinikum Carl Gustav Carus Dresden (Germany)

867020 Survival time prediction of patients with glioblastoma multiforme tumors using spatial distance measurement [8670-97]

M. Zhou, L. O. Hall, D. B. Goldgof, Univ. of South Florida (United States); R. J. Gillies,

R. A. Gatenby, H. Lee Moffitt Cancer Ctr. \& Research Institute (United States)

$86702 \mathrm{P} \quad$ Automated segmentation of brain ventricles in unenhanced $\mathrm{CT}$ of patients with ischemic stroke [8670-98]

X. Qian, Duke Univ. Medical Ctr. (United States) and Jilin Univ. (China); J. Wang, The Univ. of North Carolina at Chapel Hill (United States); Q. Li, Duke Univ. Medical Ctr. (United States) and Shanghai Advanced Research Institute (China)

$86702 Q \quad$ Multi-atlas-based segmentation of the parotid glands of MR images in patients following head-and-neck cancer radiotherapy [8670-99]

G. Cheng, China-Japan Union Hospital of Jilin Univ. (China); X. Yang, Winship Cancer Institute, Emory Univ. (United States); N. Wu, Z. Xu, H. Zhao, China-Japan Union Hospital of Jilin Univ. (China); Y. Wang, T. Liu, Winship Cancer Institute, Emory Univ. (United States)

$86702 \mathrm{R}$ Automated detection of abnormalities in paranasal sinus on dental panoramic radiographs by using contralateral subtraction technique based on mandible contour [8670-100]

S. Mori, Nihon Univ. School of Dentistry at Matsudo (Japan); T. Hara, M. Tagami,

C. Muramatsu, Gifu Univ. School of Medicine (Japan); T. Kaneda, Nihon Univ. School of Dentistry at Matsudo (Japan); A. Katsumata, Asahi Univ. School of Dentistry (Japan);

H. Fujita, Gifu Univ. School of Medicine (Japan) 
$86702 S$ Recognition of upper airway and surrounding structures at MRI in pediatric PCOS and OSAS [8670-101]

Y. Tong, Medical Image Processing Group, Univ. of Pennsylvania (United States);

J. K. Udupa, D. Odhner, Medical Image Processing Group, Univ. of Pennsylvania (United

States); S. Sin, R. Arens, The Children's Hospital at Montefiore, Albert Einstein College of

Medicine (United States)

$86702 \mathrm{~T}$ An optimal set of landmarks for metopic craniosynostosis diagnosis from shape analysis of pediatric CT scans of the head [8670-102]

C. S. Mendoza, Sheikh Zayed Institute for Pediatric Surgical Innovation, Children's National Medical Ctr. (United States) and Univ. of Sevilla (Spain); N. Safdar, E. Myers, T. Kittisarapong, Sheikh Zayed Institute for Pediatric Surgical Innovation, Children's National Medical Ctr. (United States); G. F. Rogers, Children's National Medical Ctr. (United States);

M. G. Linguraru, Sheikh Zayed Institute for Pediatric Surgical Innovation, Children's National Medical Ctr. (United States)

$86702 \mathrm{U}$ Characterization of T2 hyperintensity lesions in patients with mild traumatic brain injury [8670-103]

J. J. Caban, Walter Reed National Military Medical Ctr. (United States); S. A. Green, Franklin \& Marshall College (United States); G. Riedy, Walter Reed National Military Medical Ctr. (United States)

$86702 \mathrm{~V}$ Prediction of the potential clinical outcomes for post-resuscitated patients after cardiac arrest [8670-104]

S. Hong, B. Kwon, Seoul National Univ. (Korea, Republic of); I. D. Yun, Hankuk Univ. of Foreign Studies (Korea, Republic of); S. U. Lee, Seoul National Univ. (Korea, Republic of); K. Kim, J. Kim, Seoul National Univ. Bundang Hospital (Korea, Republic of)

POSTER SESSION: LUNG

$86702 \mathrm{~W}$ A novel approach of computer-aided detection of focal ground-glass opacity in 2D lung CT images [8670-105]

S. Li, X. Liu, A. Yang, K. Pang, Beijing Institute of Technology (China); C. Zhou, X. Zhao,

Y. Zhao, Cancer Institute \& Hospital, Chinese Academy of Medical Sciences (China)

$86702 \mathrm{X}$ Multimodal 3D PET/CT system for bronchoscopic procedure planning [8670-106]

R. Cheirsilp, W. E. Higgins, Pennsylvania State Univ. (United States)

$86702 Y$ Content-based image retrieval for interstitial lung diseases using classification confidence

[8670-107]

J. K. Dash, S. Mukhopadhyay, Indian Institute of Technology Kharagpur (India);

N. Prabhakar, M. Garg, N. Khandelwal, Postgraduate Institute of Medical Education \& Research (India)

$86702 Z$ A new 3D texture feature based computer-aided diagnosis approach to differentiate pulmonary nodules [8670-109]

F. Han, Stony Brook Univ., SUNY (United States) and Northeastern Univ. (China); H. Wang, B. Song, Stony Brook Univ., SUNY (United States); G. Zhang, H. Lu, Fourth Military Medical Univ. (China); W. Moore, Stony Brook Univ., SUNY (United States); H. Zhao, Northeastern Univ. (China); Z. Liang, Stony Brook Univ., SUNY (United States) 
867030 Integrating shape into an interactive segmentation framework [8670-110]

S. Kamalakannan, B. Bryant, H. Sari-Sarraf, Texas Tech Univ. (United States); R. Long,

S. Antani, G. Thoma, National Library of Medicine (United States)

867031 Extraction method of interlobar fissure based on multi-slice CT images [8670-111] M. Matsuhiro, H. Suzuki, Y. Kawata, N. Niki, Univ. of Tokushima (Japan); J. Ueno, Univ. of Tokushima (Japan); Y. Nakano, E. Ogawa, Shiga Univ. of Medical Science (Japan); S. Muro, M. Mishima, Graduate School of Medicine Kyoto Univ. (Japan); H. Ohmatsu, National Cancer Ctr. Hospital East (Japan); N. Moriyama, National Cancer Ctr. for Cancer Prevention and Screening (Japan)

867032 Automated lung field segmentation in CT images using mean shift clustering and geometrical features [8670-112]

C. K. Chama, S. Mukhopadhyay, P. K. Biswas, A. K. Dhara, Indian Institute of Technology Kharagpur (India); M. K. Madaiah, N. Khandelwal, Postgraduate Institute of Medical Education \& Research (India)

867033 Semi-quantitative assessment of pulmonary perfusion in children using dynamic contrastenhanced MRI [8670-113]

C. Fetita, TELECOM \& Management SudParis (France) and MAP5, CNRS (France);

W. E. Thong, MAP5, CNRS (France) and Ecole Polytechnique de Montréal (Canada);

P. OU, MAP5, CNRS (France) and Hôpitaux Necker-Enfants Malades (France)

867034 Learning-based image preprocessing for robust computer-aided detection [8670-114] L. Raghupathi, P. R. Devarakota, Siemens Corp., Corporate Technology (India); M. Wolf, Siemens Healthcare, Inc. (United States)

867035 Curved planar reformation and optimal path tracing (CROP) method for false positive reduction in computer-aided detection of pulmonary embolism in CTPA (Cum Laude Poster Award) [8670-115]

C. Zhou, H.-P. Chan, Y. Guo, J. Wei, A. Chughtai, L. M. Hadjiiski, B. Sundaram, S. Patel, J. W. Kuriakose, E. A. Kazerooni, Univ. of Michigan Health System (United States)

867036 Multiscale intensity homogeneity transformation method and its application to computeraided detection of pulmonary embolism in computed tomographic pulmonary angiography (CTPA) [8670-116]

Y. Guo, C. Zhou, H.-P. Chan, J. Wei, A. Chughtai, B. Sundaram, L. M. Hadjiiski, S. Patel,

E. A. Kazerooni, Univ. of Michigan Health System (United States)

867037 Quantitative consensus of supervised learners for diffuse lung parenchymal HRCT patterns [8670-117]

S. Raghunath, S. Rajagopalan, R. A. Karwoski, B. J. Bartholmai, R. A. Robb, Mayo Clinic College of Medicine (United States)

867038 Automated localization of costophrenic recesses and costophrenic angle measurement on frontal chest radiographs [8670-118]

P. Maduskar, L. Hogeweg, R. Philipsen, B. van Ginneken, Radboud Univ. Nijmegen Medical Ctr. (Netherlands) 
867039 3D texture analysis of solitary pulmonary nodules using co-occurrence matrix from volumetric lung CT images [8670-108]

A. K. Dhara, S. Mukhopadhyay, Indian Institute of Technology Kharagpur (India);

N. Khandelwal, Postgraduate Institute of Medical Education \& Research (India)

\section{POSTER SESSION: MULTIPLE/OTHER ORGAN SYSTEMS}

8670 3A Automatic organ localizations on 3D CT images by using majority-voting of multiple 2D detections based on local binary patterns and Haar-like features [8670-119]

X. Zhou, S. Yamaguchi, Gifu Univ. School of Medicine (Japan); X. Zhou, Nagoya Bunri Univ. (Japan); H. Chen, T. Hara, Gifu Univ. School of Medicine (Japan); R. Yokoyama, M. Kanematsu, Gifu Univ. Hospital (Japan); H. Fujita, Gifu Univ. School of Medicine (Japan)

8670 3B Computerized segmentation of ureters in CT urography (CTU) using COMPASS [8670-120] L. M. Hadjiiski, H.-P. Chan, L. Niland, R. H. Cohan, E. M. Caoili, C. Zhou, J. Wei, Univ. of Michigan Health System (United States)

\section{POSTER SESSION: MUSCULOSKELETAL}

$86703 \mathrm{C}$ Computer assisted measurement of femoral cortex thickening on radiographs [8670-121] J. Yao, Y. Liu, National Institutes of Health Clinical Ctr. (United States); F. Chen, National Institutes of Health (United States); R. M. Summers, National Institutes of Health Clinical Ctr. (United States); T. Bhattacharyya, National Institutes of Health (United States)

$86703 \mathrm{D}$ Exploring the utility of axial lumbar MRI for automatic diagnosis of intervertebral disc abnormalities [8670-122]

S. Ghosh, V. Chaudhary, Univ. at Buffalo, SUNY (United States); G. Dhillon, Proscan Imaging, LLC (United States)

\section{POSTER SESSION: PROSTATE AND ONCOLOGY}

86703 A prostate CAD system based on multiparametric analysis of DCE T1-w, and DW automatically registered images [8670-123]

V. Giannini, A. Vignati, S. Mazzetti, M. De Luca, C. Bracco, M. Stasi, F. Russo, E. Armando,

D. Regge, Institute for Cancer Research and Treatment (Italy)

$86703 \mathrm{~F}$ Temporal subtraction system on torso FDG-PET scans based on statistical image analysis [8670-124]

Y. Shimizu, T. Hara, Gifu Univ. School of Medicine (Japan); D. Fukuoka, Gifu Univ. Faculty of Education (Japan); X. Zhou, C. Muramatsu, Gifu Univ. School of Medicine (Japan); S. Ito, Daiyukai General Hospital (Japan); K. Hakozaki, S. Kumita, K. Ishihara, Nippon Medical School (Japan); T. Katafuchi, Gifu Univ. of Medical Science (Japan); H. Fujita, Gifu Univ. School of Medicine (Japan) 


\section{POSTER SESSION: VASCULAR AND CARDIOVASCULAR}

$86703 \mathrm{H}$ Segmentation of common carotid artery with active appearance models from ultrasound images [8670-126]

$X$. Yang, Huazhong Univ. of Science and Technology (China); W. He, Shanghai Jiao Tong Univ. (China); A. Fenster, Robarts Research Institute (Canada) and The Univ. Of Western

Ontario (Canada); M. Yuchi, M. Ding, Huazhong Univ. of Science and Technology (China)

867031 Automatic segmentation of the lumen of the carotid artery in ultrasound B-mode images [8670-127]

A. M. F. Santos, J. M. R. S. Tavares, L. Sousa, R. Santos, P. Castro, E. Azevedo, Univ. do Porto (Portugal)

8670 3J Assessment of implanted stent coverage of side-branches in intravascular optical coherence tomographic images [8670-128]

A. Wang, J. Eggermont, J. H. C. Reiber, N. Dekker, P. J. H. de Koning, J. Dijkstra, Leids Univ. Medisch Ctr. (Netherlands)

8670 3K A centerline-based estimator of vessel bifurcations in angiography images [8670-129] M. M. G. Macedo, M. A. Galarreta-Valverde, Univ. de São Paulo (Brazil); C. Mekkaoui, Massachusetts General Hospital (United States) and Harvard Medical School (United States); M. P. Jackowski, Univ. de São Paulo (Brazil)

$86703 \mathrm{~L}$ Automatic identification of origins of left and right coronary arteries in CT angiography for coronary arterial tree tracking and plaque detection [8670-130]

C. Zhou, H.-P. Chan, A. Chightai, J. Wei, L. M. Hadjiiski, P. Agarwal, J. W. Kuriakose,

E. A. Kazerooni, Univ. of Michigan Health System (United States)

$86703 \mathrm{M}$ Automated registration of coronary arterial trees from multiple phases in coronary CT angiography (CCTA) [8670-131]

L. Hadjiiski, C. Zhou, H.-P. Chan, A. Chughtai, P. Agarwal, J. Kuriakose, S. Patel, J. Wei,

E. Kazerooni, Univ. of Michigan Health System (United States)

Author Index

xviii 


\title{
Conference Committee
}

\author{
Symposium Chairs
}

Nico Karssemeijer, Radboud University Nijmegen Medical Center

(Netherlands)

Ehsan Samei, Duke University (United States)

Conference Chairs

Carol L. Novak, Siemens Corporate Research \& Technology

(United States)

Stephen Aylward, Kitware, Inc. (United States)

\section{Conference Program Committee}

Samuel G. Armato III, The University of Chicago Medical Center (United States)

Susan M. Astley, The University of Manchester (United Kingdom)

Kyongtae Ty Bae, University of Pittsburgh Medical Center (United States)

Matthew S. Brown, University of California, Los Angeles (United States)

Heang-Ping Chan, University of Michigan Health System (United States)

Marleen de Bruijne, Erasmus MC (Netherlands)

Thomas M. Deserno, RWTH Aachen (Germany)

Catalin Fetita, TELECOM \& Management SudParis (France)

Hiroshi Fujita, Gifu University School of Medicine (Japan)

Maryellen L. Giger, The University of Chicago (United States)

Hayit Greenspan, Tel Aviv University (Israel)

Lubomir M. Hadjiiski, University of Michigan Health System (United States)

Horst K. Hahn, Fraunhofer MEVIS (Germany)

Jong Hyo Kim, Seoul National University College of Medicine (Korea, Republic of)

Joseph Y. Lo, Duke University (United States)

Marius G. Linguraru, Children's National Medical Center

(United States)

Michael F. McNitt-Gray, University of California, Los Angeles

(United States)

Kensaku Mori, Nagoya University (Japan)

Janne J. Näppi, Massachusetts General Hospital (United States)

Meindert Niemeijer, The University of lowa Hospitals and Clinics (United States)

Noboru Niki, University of Tokushima (Japan) 
Nicholas A. Petrick, U.S. Food and Drug Administration (United States)

Ronald M. Summers, National Institutes of Health (United States)

Kenji Suzuki, The University of Chicago (United States)

Georgia Tourassi, Oak Ridge National Laboratory (United States)

Bram van Ginneken, Radboud University Nijmegen (Netherlands)

Eva M. van Rikxoort, Radboud University Nijmegen Medical Center

(Netherlands)

Rafael Wiemker, Philips Research (Germany)

Axel Wismueller, University of Rochester Medical Center (United States)

Xiaofeng Yang, Emory University (United States)

\section{Session Chairs}

1 Novel/Other CAD Applications

Carol L. Novak, Siemens Corporate Research \& Technology

(United States)

Stephen Aylward, Kitware, Inc. (United States)

2 Musculoskeletal CAD

Axel Wismueller, University of Rochester Medical Center (United States)

Kenji Suzuki, The University of Chicago (United States)

3 Lung CAD I

Kensaku Mori, Nagoya University (Japan)

Matthew S. Brown, University of California, Los Angeles (United States)

4 Lung CAD II

Eva M. van Rikxoort, Radboud University Nijmegen Medical Center (Netherlands)

Samuel G. Armato III, The University of Chicago Medical Center (United States)

5 Eye CAD

Meindert Niemeijer, The University of lowa Hospitals and Clinics (United States)

Thomas M. Deserno, RWTH Aachen (Germany)

6 Panel Discussion and Head and Neck I

Heang-Ping Chan, University of Michigan Health System (United States)

Stephen Aylward, Kitware, Inc. (United States)

7 Gastrointestinal and Liver CAD 
Janne J. Näppi, Massachusetts General Hospital (United States) Horst K. Hahn, Fraunhofer MEVIS (Germany)

8 Head and Neck CAD II

Catalin Fetita, TELECOM \& Management SudParis (France)

Hiroshi Fujita, Gifu University School of Medicine (Japan)

9 Cardiovascular CAD

Marius George Linguraru, Children's National Medical Center (United States)

Marleen de Bruijne, Erasmus MC (Netherlands)

10 Breast CAD I

Joseph Y. Lo, Duke University (United States)

Lubomir M. Hadjiiski, University of Michigan Health System (United States)

11 Prostate and Oncology

Xiaofeng Yang, Emory University (United States)

Berkman Sahiner, U.S. Food and Drug Administration (United States)

12 Breast CAD II

Georgia Tourassi, Oak Ridge National Laboratory (United States) 
Proc. of SPIE Vol. $8670867001-22$

Downloaded From: https://www.spiedigitallibrary.org/conference-proceedings-of-spie on 26 Apr 2023 Terms of Use: https://www.spiedigitallibrary.org/terms-of-use 